\title{
La democracia argentina ante el cambio de ciclo. Los desafíos en el epílogo de la "década larga" kirchnerista
}

\section{The Argentine Democracy Facing the Cycle Change. The Challenges in the Kirchnerist's "Long Decade" Epilog.}

\section{Mariano Aguas}

Recepción: 28 de Agosto de 2015

Aceptación: 4 de septiembre de 2015

\section{Resumen}

A pesar de haber gozado durante varios años de un amplio consenso, el Kirchnerismo no ha logrado superar su carga genética peronista ni lograr una declamada y denunciada hegemonía. A pesar de haber realizado cambios notables en la cultura y prácticas políticas, abandona el gobierno sin haber podido superar el esquema institucional imperante, ni haber solucionado problemas de fondo del sistema político argentino.

Palabras clave: kirchnerismo, hegemonía, legitimidad, populismo, democracia.

\begin{abstract}
Notwithstanding the large period with a high popular consensus, Kirchnerism has not been able to succeed in overcoming its peronist genetic heritage or in stablishing a pretended and denounced hegemony. In spite the remarkable changes accomplished regarding culture and political practices, she leaves the power without either having fixed structural difficulties of the Argentinian political system or overcoming the former institutional framework.
\end{abstract}

Keywords: kirchnerism, hegemony, legitimacy, populism, democracy. 


\title{
Introducción
}

\section{1 comenzar estas reflexiones y tentativo análisis sobre el estado del régimen democrático argentino, me vienen a la mente esas certeras palabras de Lope Vega en Un Soneto:}

\author{
"Un soneto me manda a hacer Violante, \\ que en mi vida me he visto en tal aprieto \\ catorce versos dicen que es soneto \\ burla burlando van los tres delante"
}

Sin ningún ánimo de compararme con ese genio de las letras castellanas, tomo sin embargo su idea, para tratar de explicar lo intricado que se esconde detrás del inocente requerimiento de un trabajo sobre la democracia en la República Argentina actual.

Como algunos lectores tal vez sepan, mientras escribo estas líneas en la República Argentina se desenvuelve y transcurre la competencia electoral tal vez más complicada desde el reinicio democrático que tuviera lugar en 1983 por su propio desarrollo y características, y además porque marcan, a mi criterio, el fin de un ciclo político inaugurado por la primer presidencia del matrimonio Kirchner. Esas noticias que aparecen como crónica política a diario en los medios argentinos, esconden interesantes indicadores del estado del desarrollo del régimen democrático argentino ${ }^{1}$.

Tal como ocurre en otros países de la región, según los medios consultados podemos encontrarnos con relatos que puestos en paralelo, parecieran hablar de dos (al menos) países diferentes. Así, el relato oficial de un "modelo de desarrollo con inclusión social" con intención refundadora del orden institucional impulsado por un declamado sentido progresivo (a partir del segundo mandato de Cristina Fernández de Kirchner), convive, junto a otro opositor que también invoca al progreso pero refiere al país político-social y a las políticas del oficialismo como

1 Desarrollo entendido como mero devenir. 
una involución "populista" 2 con ribetes autoritarios cuasi pre-modernos (Germani, 2003) de la más baja calidad republicana e institucional.

De manera inmediata uno se vería en la tentación de creer que alguno de estos relatos/miradas tan opuestos entre sí miente; sin embargo, luego de escrutar un poco con ojo atento, comienza a revelarse una segunda interpretación. Eso que llamamos la democracia argentina es de hecho una realidad multifacética que según desde qué ángulo se la observe presentará características muy diversas. Ambas visiones podrían ser claramente los extremos de un continuo que abarque variados matices.

Este artículo no pretende ser una interpretación analítica del discurso político. Aunque más de una vez haga uso del análisis de los relatos en competencia que intentan "formatear" la interpretación de la realidad. Dichos relatos, invocando principios de legitimidad no siempre compartidos, son precisamente materiales muy útiles para rastrear lo que a mi juicio es uno de los peligros más complejos que enfrenta la sociedad argentina: dos visiones, a veces excluyentes de legitimación política que parecieran retrotraer a la sociedad argentina a un difícil pasado previo a 1983 (Botana, 1977), o dicho de otro modo, ¿cuánto Carl Schmitt admite una democracia en proceso de consolidación?

Cualquier politólogo o estudioso dedicado al tema de la democracia sabe de la complejidad de variables aglutinadas y "escondidas" en eso que llamamos La Democracia. Precisamente debido a ello, es que la literatura es profusa en términos usados para explicar la democracia contemporánea en la República Argentina adjetivándola como delegativa (O’Donnell, 1997), hiperpresidencialista (Nino, 1992), populista (Laclau, 2005), o simplemente peronista, al decir de la colega María Esperanza Casullo en el último número de la revista Nueva Sociedad (Julio-Agosto 2015).

Quien lea estas líneas se preguntará por qué por un lado formulo la pregunta sobre Carl Schmitt, y de alguna forma la vinculo con construcciones teóricas como las de O’Donnell, Nino, Laclau u otros. Y por otro, llamo la atención sobre una hipotética regresión a clivajes y con-

2 Populista en el sentido más negativo del lenguaje común. 
flictos sobre legitimidad democrática que se creyeron superados a partir de la transición en 1983. Pues porque precisamente ese autor "maldito" durante mucho tiempo para gran parte de los teóricos de la democracia por su filiación a una derecha dura y antiliberal, paradójicamente ha sido rescatado por lo que podríamos denominar la Nueva Izquierda que reivindica al modo populista de construcción política (Mouffe, Laclau, y otros), reintroduciendo de manera muy interesante la dimensión amigo-enemigo como uno de los ejes fundamentales para reconceptualizar dicha construcción, o tal vez para ser más precisos, el antiliberalismo schmittiano puede ser una clave explicativa del comportamiento institucional y político reciente, así como un arma crítica eficaz contra la democracia burguesa/liberal/republicana (Mouffe, 2007).

A mi criterio entonces, poner el acento sobre el tema de la legitimidad y sus posibilidades de construcción en ambientes cambiantes (aunque no de manera excluyente) ayudaría a observar y comprender el estado de la democracia argentina durante la era Kirchner, entendiéndola como un ciclo que dejará su marca en la historia, y como ya lo viene haciendo, en la literatura especializada (Malamud/De Luca, 2012; Acuña, 2013).

\section{El nuevo soberano en la excepcionalidad}

\section{La excepcionalidad emergente}

Creo que resultaría muy difícil comprender la densidad y profundidad del actual clivaje, si no tuviésemos en cuenta como antecedentes recientes las crisis de los años 80 en Argentina y la región ${ }^{3}$, y en forma más específica la traumática crisis del año 2001 y el final abrupto de la convertibilidad $^{4}$ que entre otras consecuencias junto al colapso de la

3 La década "perdida".

4 Plan ideado por Domingo Cavallo, ministro de Carlos Menem para combatir la hiperinflación de fines de los ' 80 y principios de los '90 que ató el peso al dólar estadounidense en paridad uno a uno. 
economía, prácticamente licuó al sistema de partidos y sumió a gran parte de la sociedad argentina en un estado complicadamente anómico respecto de la clase política (el "que se vayan todos" fue una consigna muy divulgada entre la ciudadanía indignada y enojada) 5 .

Dichos procesos pusieron a muy dura prueba la calidad de la consolidación democrática, no tanto por el posible retorno de un régimen autoritario, sino porque debilitaron y comprometieron la capacidad política de los gobiernos hacia fines del mandato de Alfonsín, al comienzo del primer mandato de Menem y sobre todo a partir de la renuncia anticipada del gobierno de la Alianza, que encabezara Fernando De la Rúa (Pérez Liñán, 2009). La sensación dominante en la crisis del 2001 fue la de falta de gobierno y peligro de disolución a raíz de una crisis socioeconómica sin antecedentes.

Ese escenario conformó una situación de excepcionalidad que sentaría las bases de un nuevo ciclo político a partir del gobierno provisional de Duhalde (ungido como tal por una liga de gobernadores luego de una semana de varios intentos presidenciales fallidos), y sobre todo a partir de la llegada de Néstor Kirchner al poder a través de un proceso eleccionario que procurará algo de legitimidad de origen a pesar de haber obtenido el 22, $2 \%$ de los votos contra Carlos Menem que obtuviera el 24,5\% en un escenario donde el peronismo concurrió dividido. Como Menem declinó presentarse al balotaje, Kirchner fue consagrado triunfador.

Antes de adentrarnos definitivamente en la década larga ${ }^{6}$ kirchnerista, creo necesario remarcar las características que presenta el panorama político argentino entre principios de 2002 (asunción de Duhalde) y 2005 (las primeras elecciones legislativas en el ciclo kirchnerista). En esos tres años se van a cimentar a mi criterio lo que podríamos llamar las bases de la excepcionalidad emergente:

5 Plan ideado por Domingo Cavallo, ministro de Carlos Menem para combatir la hiperinflación de fines de los '80 y principios de los '90 que ató el peso al dólar estadounidense en paridad uno a uno.

6 La llamo década larga porque su duración real es de 12 años. 
- Crisis institucional;

- Resurgimiento del poder territorial;

- Cambio en las condiciones externas y salida de la convertibilidad.

\section{Crisis institucional}

\section{a) Reconstruyendo la presidencia}

La crisis institucional en la Argentina de comienzos de siglo se manifestó básicamente en dos dimensiones: debilitamiento de la autoridad presidencial y mutación del sistema de partidos a través del aumento de la fragmentación que modificó hasta el presente al bipartidismo imperante desde la restauración democrática de 1983. Para un país con diseño institucional y cultura política presidencialista como Argentina, la dilución del poder y el deterioro de la autoridad del presidente De la Rúa, fue un trauma muy profundo para la sociedad, así como un desafío nada fácil que la clase política debió enfrentar.

No fue casual que una de las primeras medidas del presidente Duhalde fuera convocar a las organizaciones de la sociedad civil a través de lo que se llamó El Diálogo Argentino, el cual hizo por una parte de caja de resonancia organizada de la protesta y las propuestas de la sociedad civil, y por la otra de factor legitimante para la endeble estructura de autoridad que emergía luego del descalabro político/institucional. Dicha autoridad tenía por delante una situación socioeconómica muy compleja, con una sociedad cuyo índice de pobreza llegaba por primera vez en la Argentina moderna a cerca del $50 \%$ de la población y con el vínculo representativo muy dañado.

$\mathrm{Si}$ a esto agregamos la tradición movilizante de la cultura sindical argentina forjada en una historia de pleno empleo durante gran parte del siglo XX, más la memoria de un tiempo pasado feliz y perdido para clases medias y bajas, queda claro que el panorama era potencialmente explosivo. De hecho, como resultado de la represión policial de una pro- 
testa organizada por agrupaciones piqueteras ${ }^{7}$ en el sur del conurbano bonaerense, se produce la muerte de dos jóvenes militantes de asociaciones barriales. El escándalo político derivado de ese trance le iba a truncar a Duhalde las posibilidades para presentarse como candidato a elecciones luego del proceso normalizador pactado con los gobernadores.

No pudiendo ser él quien reiniciara en forma institucional normal el nuevo ciclo, Duhalde procuró dos cosas de mínima: que Carlos Menem no volviese a la presidencia (para lo cual dividió al peronismo, inventando el Frente Para la Victoria) y que a pesar de la división, el peronismo no corriera la suerte de la Unión Cívica Radical, socio "mayoritario" de la mal hadada Alianza para el Trabajo, la Justicia y la Educación con el FREPASO (Frente País Solidario) vistos como los responsables de la debacle. Teniendo esto en mente, Duhalde elegiría como su candidato y delfín a un cuasi ignoto gobernador de la austral provincia de Santa Cruz, Néstor Kirchner.

\section{b) Metamorfosis del sistema de partidos}

Luego de los traumas que el péndulo cívico militar dejara como enseñanza en la clase política argentina, la nueva democracia iba a construir un tablero político con nuevos "fusibles" que garantizaran que las crisis políticas no terminasen con el régimen como antaño. ¿Pero quién obraría como fusible ante una eventual crisis sistémica? Para Raúl Alfonsín, ex presidente y líder radical, esa función debería ser responsabilidad de un nuevo diseño institucional. Cobra entidad entonces la figura del ministro Jefe de Gabinete.

Dicha figura aparece en la constitución reformada en 1994, como producto de la negociación entre un Menem que aprovechando en aquel momento su alta popularidad, buscaba la reelección hasta entonces prohibida y un Alfonsín que por su lado buscaba nuevos mecanismos de salvaguarda de corte semipresidencialista que "contuviesen" a un peronismo no siempre respetuoso de ciertas prácticas republicanas.

7 Las organizaciones llamadas piqueteras, debido a su metodología de protesta y visualización política, fueron surgiendo a medida que el índice de desempleo fuera creciendo en forma progresiva desde el segundo mandato del presidente Menem. 
Por lo visto, si bien la reforma fue implementada, los presidentes argentinos posteriores al 95 no delegarían poderes y centralidad política haciendo en la práctica del nuevo ministerio una cuasi secretaría presidencial....Dicha conducta, entre otras causas, hizo que de facto, quienes fungieron como fusibles sistémicos fueran los partidos, sobre todo aquellos más ligados a sectores medios urbanos como la UCR más permeables a la indignación y el desencanto y con una "identidad" política más leve que los sectores más populares identificados con el peronismo (Torre, 2003).

Como resultado de ese proceso, el bipartidismo que caracterizó al sistema de partidos argentino desde 1983, luego del 2001 comienza a fragmentarse y durante la década kirchnerista irá mutando a un sistema que podríamos denominar multipartidista con partido dominante (Mustapic, 2013).

\section{Resurgimiento del poder territorial}

Entrando al siglo XXI, la República Argentina sufre una llamativa paradoja fruto de la crisis descrita, su sistema político sufre una regresión que lo lleva a funcionar en algunos aspectos como lo hiciera en el siglo XIX. El amable lector debe tener en cuenta que el país de los argentinos es como otros de la región, una construcción moderna que se origina en los movimientos independentistas de las colonias españolas de principios del siglo XIX. Debido a la extensión y características de su territorio, así como a la herencia institucional de España (en especial las reformas borbónicas), Argentina luego de una larga guerra civil que consumió prácticamente cuarenta años de su historia luego de las guerras de independencia, por fin hacia fines del siglo XIX logra plasmar un modelo político institucional balanceado entre un poder central fuerte, $y$ un diseño federal que asegura a cada provincia poder de veto sobre temas fundamentales para el gobierno de la nación (Oszlack, 1997). No es el propósito de este artículo profundizar sobre esos temas, pero, no sería muy inteligente soslayar el hecho que las provincias en tanto entes políticos, preceden a la organización de la nación. 
Por lo tanto, desde 1880 cuando se federaliza la ciudad de Buenos Aires ${ }^{8}$ hasta fines del siglo pasado vamos a ser testigos, entre otras cuestiones, de los ingentes esfuerzos de ingeniería política para llegar a acuerdos sobre grandes temas que afectan la gobernabilidad del país. Instrumentos insustituibles para dichos esfuerzos han sido los grandes partidos nacionales. Primero el Partido Autonomista Nacional, fiel exponente del orden conservador y de la etapa predemocrática (Botana, 1977). Luego, con el advenimiento de las masas a la escena política y su consecuente democratización, aparecen primero la Unión Cívica Radical (UCR) y luego el Partido Justicialista (PJ). Estos últimos, hasta la crisis de 2001 cumplieron en tanto grandes partidos modernos de masas con presencia en todo el territorio del país, el rol de articuladores de demandas e intereses entre la nación y las provincias.

La tremenda crisis junto a otros factores ${ }^{9}$ hizo que debilitados los partidos, el poder volviese a sus primitivos orígenes, el territorio. Dicho proceso hizo que cada gobernador actuase como un jefe político independiente, y hasta los intendentes (alcaldes) de los populosos municipios que rodean a la ciudad de Buenos Aires (el cono urbano) se erigiesen en los nuevos barones y árbitros de la política nacional. Llegado su momento, Néstor Kirchner tomaría cautelosa nota de esa nueva realidad.

\section{Cambio en las condiciones externas y salida de la convertibilidad}

Como sostiene Ludolfo Paramio (2006: 45)

"La crisis económica y política en Argentina, en diciembre de 2001, marcó probablemente el fin del Consenso de Washington. El FMI había presentado durante demasiado tiempo a este país como el mejor ejemplo del nuevo modelo económico, y la convertibilidad arrastró en su colapso la credibilidad de esta institución y de los organismos multilaterales. Lo que no deja de ser paradójico, si se tiene en cuenta que

8 La federalización de la ciudad de Buenos Aires se hizo a expensas de la provincia homónima.

9 De hecho la crisis de los partidos es un fenómeno de alcance mundial (Rosanvallon, 2007). 
la convertibilidad no formaba parte del decálogo de Washington, y que muchos de los que defendían las reformas habían señalado sus graves riesgos al menos desde 1996."

La salida de la convertibilidad realizada por el staff del gobierno de Duhalde en el 2002, Remes Lenicov primero y Lavagna después, y el nuevo cambio competitivo del peso respecto al dólar estadounidense, si bien implicó cirugía mayor y no siempre con anestesia, devolvió al sistema productivo argentino una poderosa arma de recuperación, que permitió utilizar una respetable capacidad productiva mantenida por varios ańos en estado casi ocioso debido al corsé que representaba la convertibilidad.

Por otro, la continua recuperación del precio de los commodities producidos en forma altamente eficiente por el sector agrario, encontrará en la expansión de las economías emergentes, principalmente China y la India una potente demanda e incentivo a la inversión. De esta forma van a empezar a consolidarse los comienzos de un ciclo macroeconómico virtuoso que le iban a permitir a la Argentina estabilizarse; expandir su economía; armar un sistema de protección social para los sectores más castigados por las políticas neoconservadoras y fundamentalmente comenzar a desendeudarse con el exterior.

Dicho esquema resultó tan adecuado, que el propio Kirchner en campaña electoral durante el 2003 anunció que el ministro Lavagna (padre de la ingeniería de la recuperación económica) y su equipo continuarían con su gobierno, sin dudas fue una medida política, económica y electoral muy acertada.

\section{El ciclo K inicia}

Anteriormente sostuvimos que el ciclo político de los Kirchner puede ser comprendido temporalmente como una década larga, a través de la cual podemos distinguir al menos tres períodos: 
- La etapa excepcional, ya presentada;

- El despliegue del modelo K;

- La consolidación y el problema sucesorio.

\section{El nuevo soberano se despliega}

Si bien en términos institucionales, Néstor Kirchner asume la presidencia de la nación en mayo de 2003, durante ese año y el 2004 su política diferirá poco del modelo heredado de su antecesor, continuando su inercia fundamentalmente en lo que hace a la economía. Precisamente, continuar con dichas políticas más el sostenimiento de la alianza estratégica con un Duhalde hasta ese entonces caudillo indiscutido del peronismo de la provincia de Buenos Aires ${ }^{10}$ le van a permitir a Kirchner ir construyendo un poder que le resultará indispensable para llevar a cabo su modelo de conducción política, mientras se congracia con una sociedad que ve con buenos ojos la reconstrucción de la autoridad presidencial en torno a valores compartidos y formas desestructuradas de su ejercicio ${ }^{11}$.

Los argentinos habían elegido como presidente a alguien poco conocido en el todavía complejo 2003, y pronto comenzarían a conocerlo.

\section{"Parricidio" y acumulación de poder}

Como dice Luis Tonelli (2012: 21)

"Para el kirchnerismo, compartir el poder ha sido considerado un acto de extrema necesidad -o sea, un acto de extrema debilidad-. De allí que en vez de replicar en su crecimiento el Big Bang al que aspira toda fuerza política y expandirse, diferenciarse y jerarquizarse, el kirchnerismo en su ascenso exhibe más bien un Big Crunch.”

10 La provincia con mayor peso electoral relativo.

11 "Un Flaco como cualquier otro", al decir del intelectual José Pablo Feinmann. 
Por supuesto que el concepto parricidio es usado como una metáfora política, ¿por qué? porque como buen caudillo peronista, y en general como buen político realista, Kirchner se da cuenta de que para desarrollar su plan de gobierno y acumulación de poder, debe "matar" políticamente a Eduardo Duhalde. El cuándo y el cómo serían claves, como siempre.

Como dijimos, $\mathrm{NK}^{12}$ necesitaba reconstruir la autoridad presidencial y al mismo tiempo su poder, no sólo porque es lo que manda el manual del buen "Príncipe" desde Maquiavelo hasta nuestros días, sino porque en parte la misma sociedad argentina se lo demandaba, sobre todo lo primero. Dicha situación le presentaba una oportunidad de oro, claro que para ello debía derrotar políticamente a su mentor Duhalde, y al peronismo que no resultase dócil a su voluntad.

Para comenzar a construir su propio perfil, el kirchnerismo echa mano a recursos de bajo costo político y alto rendimiento e impacto como la diferenciación con la "vieja política"; la resignificación de la causa de los derechos humanos que convierte en bandera distintiva; una revalorización del ideario de las juventudes políticas diezmadas durante la última dictadura y una cierta versión simplificada de tensión entre izquierda y derecha; y la continuación en nueva clave de las políticas asistenciales implementadas por el gobierno anterior.

Estas estrategias contarán con el apoyo entusiasta de vastos sectores de la sociedad, fundamentalmente los jóvenes que como niños o adolescentes habían vivido las épocas neoconservadoras de Menem y el catastrófico final de la Alianza y la convertibilidad, y que ahora comenzarán a politizarse, mientras la economía crece a tasas chinas a un promedio entre 2003 y 2008 de 8,5\%. Estas políticas serán coronadas con un triunfo holgado por el 38,3\% del Frente Para la Victoria triplicando al competidor más cercano, la UCR, en las elecciones legislativas de 2005 (Zelaznik, 2012). Cabe aclarar que dicho porcentaje significó un 47,2 \% de las bancas en diputados, lo cual dejaba al kirchnerismo casi en situación de manejo propio de dicha cámara, más un senado altamente amigable.

12 Néstor Kirchner. 


\section{Crisis, bienaventurada crisis}

Por otro lado, haciendo de la necesidad virtud, el kirchnerismo descubre que dada la fragmentación de partidos opositores así como del propio peronismo, y la nueva realidad "territorialista" del sistema político post debacle; una política macroeconómica a la vez expansiva pero equilibrada y paulatinamente superavitaria, podía presentarse como una excelente oportunidad para replicar el modo radial de conducción y construcción política ya ensayado y desarrollado en Santa Cruz. ¿Cómo? con el manejo discrecional de los fondos públicos. Pero para eso se necesitaba seguir alimentando el fantasma de la crisis, que permitiese seguir estirando la situación de emergencia tributaria y justificadora del modo decisionista de $\mathrm{NK}^{13}$.

Con un congreso entusiastamente dócil, sellado por una mayoría cuasi propia que delegaba poderes Legislativos al poder Ejecutivo, la reasignación de partidas presupuestarias y el uso profuso de decretos de necesidad y urgencia ${ }^{14}$, serían ya una marca indeleble del modo kirchnerista de conducción y gestión política schmittianamente NK decidía soberanamente en el Estado de Excepción y bajando de paso los "costos de transacción" (Tsebelis, 1990).

"El kirchnerismo se nos presenta, entonces, como un intenso fenómeno de poder a secas (algo que está implícito en lo líquido de su carácter transgresor) antes que como voluntad de construcción política e institucional con aspiraciones a una cierta permanencia. Es un emergente de la gran crisis de 2001, que en una fuerte demostración de capacidad

13 El kirchnerismo procurará instalar la idea de que la crisis del 2001 comienza a ser superada sólo con la llegada NK a la presidencia, omitiendo lo ya explicado de manera intencional. Por otro lado, el recurso al concepto crisis es usado hasta estos días a modo de legitimación del carácter decisionista de conducción política.

14 Un decreto de necesidad y urgencia (DNU) es un tipo de norma existente en la Argentina que, a pesar de ser sancionada solo por el Poder Ejecutivo, tiene validez de ley. Una vez promulgado el DNU, el Congreso debe analizarlo y determinar si continúa vigente o no. Este tipo de legislación está contemplado en el artículo 99 de la Constitución Nacional. El presidente Néstor Kirchner firmó 270 en cuatro ańos y medio de mandato (Zelaznik, 2012). El presidente Alfonsín firmó 10 en casi seis años. 
gubernativa brinda respuesta a la preocupación existencial que sigue asolando a la conciencia colectiva argentina: el terror al vacío de poder. Es por esa razón que no avanza demasiado ni en la reconstrucción institucional del Partido Justicialista ni en la conformación de una nueva fuerza política, quedando en el desván de las buenas iniciativas tales como la transversalidad o la Concertación Plural con las que amenazó trastocar las líneas tradicionales del enfrentamiento partidario para otorgarle una dinámica ideológica de izquierda contra derecha. Al contrario, ha generado alternativas incluyentes amorfas, espacios sin jerarquías ni formalidades, redes de simpatizantes y personalidades, como en su momento Compromiso K." (Tonelli, 2012).

Como podemos ver, cierto uso discrecional de las partidas presupuestarias ayudaron al kirchnerismo tanto a superar los escollos producidos por la crisis, así como aquellos resultantes de la falta de construcción política, y por otro lado a opacar a los nuevos enemigos como Duhalde, devenido en "mafioso" y representante de lo "viejo" a superar en el gesto fundante del nuevo relato. La clave fue el manejo de los fondos para obra pública y la gestión concentrada en la casa rosada de dichos recursos mediante los cuales el kirchnerismo pudo establecer alianzas con la "Liga de Gobernadores e Intendentes del Cono Urbano", respetando la territorialidad pero haciéndola dependiente del erario nacional.

Dicha realpolitik fue replicada con otros sectores de poder como sindicatos, empresarios, organismos de DD.HH y cualquier otro grupo representativo de la sociedad, lo que permitió poder armar divisiones en el seno de las mismas, al mejor estilo divide et impera. Mientras tanto, dicha táctica "conservadora" era acompañada de un discurso y una actitud transgresora que simbólicamente redefinía a la democracia en términos de conflicto, en su mejor estilo "setentista" y agonal pero aggiornada a los modos mediáticos de la sociedad moderna (¿postmoderna?), cuyo sujeto activo no es más ese Pueblo típico del discurso populista clásico, sino "la gente". 


\section{El conflicto y el gobierno de la opinión pública}

El kirchnerismo, que en 2003 nace minoritario y bajo la tutela del hombre fuerte del momento, Eduardo Duhalde, poco a poco irá construyendo un "gobierno de la opinión pública" con una popularidad lograda a base de hechos espectaculares, que por cierto no desmerecen el alcance político de los mismos, y que van a tener generalmente un factor en común: el conflicto como herramienta de construcción. El conflicto y la lógica amigo-enemigo, serán en el manual de construcción política kirchnerista, elementos centrales.

Como dijéramos antes, los Kirchner eran conscientes de la necesidad de construir nuevos horizontes valorativos que les generasen poder propio. Dichos horizontes debían hacer de instrumentos simbólicos para volver a politizar y generar sentido en la sociedad, así como construir poder a través de la sensación de eficiencia en la toma de decisiones. La relación amigo-enemigo sería muy bien explotada para la construcción de un Nosotros (la buena gente, la Mayoría de hombres y mujeres comunes) enfrentada en el momento agonal con un Ellos, los otros, o sea la Minoría de poderosos. De esta forma, cuando el oficialismo gana sus batallas, una épica de la victoria refuerza la tranquilizadora y confortable sensación de gobernabilidad (Tonelli, 2012).

Dicha épica basada en conflictos elegidos para vencer y generar la sensación de comando y eficacia en una sociedad temerosa del vacío de poder y sus consecuencias sirvió como un sustituto funcional a la acotada institucionalidad que el kirchnerismo fatigaba en construir. Esa táctica sin embargo encerraba un peligro para el relato victorioso y transformador, ya que precisamente aquello que generaba su fortaleza en el "enemigo" derrotado, cuando el gobierno sufría un traspié ponía al país en el umbral del infierno tan temido: la vuelta de la ingobernabilidad y la crisis sistémica.

Prueba de ello fue la derrota política del oficialismo en 2008 durante el conflicto con el sector agropecuario, o la derrota legislativa en 2009 producto de las llamadas candidaturas testimoniales, pensadas para trac- 
cionar votos a partir de una candidatura nominal de una figura política que en realidad no tendría la voluntad de asumir dicho cargo Legislativo la cual aportaría su "carisma", lo peor fue que la sociedad lo sabía. Sin embargo, los Kirchner demostraron también gran capacidad para generar hechos que aportasen a la construcción de poder así como una notable capacidad de recuperación política luego de sonadas derrotas.

El acto en el Colegio Militar de la Nación donde Kirchner manda al Jefe de Estado Mayor del Ejército descolgar el cuadro de Videla ${ }^{15}$, o la exitosa quita de la deuda externa lograda a partir de durísimas negociaciones que demostraron la capacidad del equipo económico así como la firme decisión presidencial, generaron un importante aumento del capital político del presidente y los suyos. Dicha capacidad política les permitió a los Kirchner superar una compleja característica de la nueva democracia argentina. Esa característica o cuasi "ley de hierro" de la restaurada democracia argentina, rezaba que una derrota del oficialismo en elecciones de renovación parlamentaria presagiaba una derrota ineludible en las presidenciales subsiguientes. Sin embargo, luego de la derrota electoral en la parlamentarias del 2009, en el 2011 Cristina Fernández de Kirchner sería reelecta como presidenta de la República.

Antes de ello, en el 2007, cuando todo era más tranquilo, el Frente para la Victoria presenta a Cristina como candidata a presidenta sucediendo de esta forma a su marido, Néstor Kirchner. La continuidad estaba garantizada.

\section{Consolidación exitosa y sucesión problemática}

La llegada de Cristina Fernández al poder por el 45,3\% de los votos y a más de 22 puntos de diferencia con el segundo (la Coalición Cívica, 23\%) marca dos cosas. La primera es la instauración de una forma de alternancia en el poder pensada a largo plazo, y la segunda, el amplio apoyo de la sociedad al programa político vigente.

15 Ex miembro de la Junta de Gobierno del Proceso, y ex presidente de la última dictadura militar. 
A este respecto, merece una breve mención el hecho de que Roberto Lavagna, el "ingeniero" de la recuperación económica, la exitosa negociación de la deuda externa y garante de la continuidad en el pasaje de Duhalde a Néstor Kirchner, se presentara como competidor a la primera magistratura de la mano de la Unión Cívica Radical en el espacio Una Nación Avanzada y que obtuviera el tercer puesto con un 16,9\% de los sufragios. Más allá del dato electoral, lo relevante de este hecho, es que muestra un segundo quiebre en la "élite/coalición" que condujera la exitosa transición y puesta en marcha del ciclo. Eso resulta en un muy buen indicador de que algo estaba cambiando.

Lavagna decide abandonar el gabinete del presidente Kirchner a fines del 2005 luego de tres ańos y medio de exitosa gestión al chocar su visión con la del presidente quien prácticamente le pidió la renuncia ${ }^{16}$. Fiel a su estilo, Kirchner no soportaba alguien con perfil propio en su gabinete. Por otro lado la situación macroeconómica floreciente y las "cajas" llenas le permitirían al presidente ir delineando una nueva etapa con "su" proyecto macroeconómico, y por qué no, con mayor discrecionalidad.

Si bien el 2007 marca la llegada de un nuevo gobierno K, la nueva ingeniería de gobierno se consolida a mi criterio a partir del 2006 con la salida de Lavagna y su reemplazo por Felisa Micheli, alguien que no tendría problemas en subordinarse a las directivas del núcleo de poder, o "la mesa chica" como comúnmente se le llamó al matrimonio Kirchner más Alberto Fernández, su ministro Jefe de Gabinete.

\section{La épica del estatalismo recargado}

La paulatina recuperación del país a partir del 2002 permitió a un go-

16 Entre otros temas, iniciando el 2005 hubo profundas diferencias entre Kirchner y Lavagna respecto de las tasas y estrategias de crecimiento. Mientras el primero quería fomentar el crecimiento a tasas altas apalancándose en la expansión acelerada del consumo interno, el segundo sostenía que tasas un poco menores generarían crecimiento pero aventando el peligro inflacionario. Parece que el tiempo le dio la razón a Lavagna. 
bierno que nació débil contar con herramientas utilísimas a la hora construir poder y luego construir un relato sobre el mismo. Como hemos visto, parte de la virtud política del matrimonio Kirchner ha sido usar la crisis como el fantasma tan temido y aleccionador, al mismo tiempo que instaurar un relato que oculta cualquier reconocimiento a la recuperación iniciada por Duhalde. De esta manera, los únicos "pastores" que llevarían a la sociedad argentina a buenas pasturas y aguas mansas serían ellos mismos.

\section{Como dice Marcos Novaro (2012: 3)}

"Al igual que el Alfonsinismo y el menemismo, el kirchnerismo contó con ventajas iniciales para crear una amplia corriente de adhesión favorable a sus líderes y sus ideas, y para darle alcance *epocal* a este nuevo consenso, es decir, presentar su llegada al poder como la ocasión para producir un corte en el proceso histórico e iniciar una etapa completamente nueva, llamada a perdurar. Una feroz crisis social y económica había estallado poco tiempo antes, los demás actores políticos y sociales se hallaban en alguna medida debilitados o deslegitimados por sus responsabilidades reales o aparentes en esa crisis, y la sociedad buscaba un nuevo *relato* que le permitiera interpretar las desgracias que se padecían como el trago amargo pero necesario para dejar atrás los problemas. En todo esto, en el uso de la crisis como oportunidad para un proyecto refundacional, el kirchnerismo no desentonó ni innovó."

Para un gobierno exitoso, sabemos que la virtud política debe estar acompañada de una fortuna amable. Entre los restos del país político y social post crisis los Kirchner encontraron una distribución de recursos y adversidades más favorable para el ejercicio del poder.

$\mathrm{Ni}$ los empresarios ni los organismos financieros internacionales, ni los gobiernos de países acreedores tenían el poder de veto que habían detentado en 1989 debido a la crisis de la deuda o la hiperinflación, ni las cúpulas sindicales y otros sectores contaban con el que habían retenido a partir de 1983. Con dicho cuadro de situación, los Kirchner comen- 
zarían una serie de reformas que mejorarían claramente la institucionalidad del sistema, como la promoción de un recambio de la Corte $\mathrm{Su}$ prema de Justicia seleccionando jueces de alto perfil profesional en vez de político, o el reconocimiento de nuevas dirigencias sindicales como la Central de Trabajadores Argentinos y la de sectores de desempleados. Dichas medidas sirvieron a la construcción de un creciente prestigio y apoyo de la sociedad, que hacían suponer que el camino K estaba en un lugar intermedio entre populismos radicalizados como el venezolano o boliviano, y el progresismo moderado y conciliador a la chilena.

La lógica "neodesarrollista" o "neokeynesiana" que abraza el gobierno para leer y gestionar la relación Estado-mercado será la contraparte de un relato político que de a poco y a medida que el poder se fue consolidando, va ir acercándose a visiones más ligadas a las teorías y diagnósticos sobre la democracia que poniendo el eje en el momento agonal, procurará la construcción de campos políticos delimitados por la relación amigo-enemigo representados en la lucha del "interés nacional y de las mayorías" contra "las corporaciones y poderes monopólicos minoritarios".

Para ello la estrategia discursiva construyó desde el relato su propia síntesis de viejas tradiciones nacionales, desde un neorevisionismo de la historia de la independencia y organización nacional durante el siglo XIX, la tradición irigoyenista del partido radical, hasta una reinterpretación del peronismo histórico rescatado desde la figura de Eva Perón, reconstruyéndola como revolucionaria desde su rol femenino (donde claramente Cristina se refleja) para proyectarse en el discurso nacional-revolucionario de las juventudes políticas de la década del setenta, rescatando desde allí una continuidad épica cuyo aggiornamiento y natural heredero casi en clave postmoderna, sería el kirchnerismo. Podríamos afirmar entonces que el kirchnerismo resignifica, y con ello politiza en sentido agonal, eso que en Argentina se denomina "El Pensamiento Nacional"17.

17 Denominación algo vaga pero que condensa un abigarrado grupo de intelectuales y liderazgos políticos, cuya identidad básicamente se define en contra de lo que es considerado un pensamiento cipayo y extranjerizante. 
Dicha visión sostiene entre otros principios un activo rol del Estado como demiurgo libertador de la sociedad y la nación a las que necesariamente hay que "salvar" de intereses egoístas y arteros que buscan someterla. Esta división en el marco discursivo y del sentido producirá lo que comúnmente se denomina "La Grieta", con profundas consecuencias en el campo cultural, académico y sobre todo periodístico y mass-mediático.

Como emblema de este clima, resulta paradigmático el conflicto del gobierno con el grupo Clarín (elegido como enemigo principal), a partir del rol que este grupo empresarial jugara a favor de los intereses agropecuarios durante la crisis del 2008 por el tema retenciones al agro. La respuesta gubernamental fue el impulso de la llamada ley de Servicios de Comunicación Audiovisual (Ley 26.522). Dicha normativa junto a buenos intentos para una mejora del sector, fue de todos modos pensada para afectar al citado grupo empresario. Todo esto sin olvidar que durante la presidencia de NK su estrategia de comunicación fue tan centralizada y unidireccional como dependiente de medios privados, particularmente del grupo Clarín.

Esquema sucesorio herido y el afianzamiento del "Modelo"

El despliegue creciente de la épica y “cultura K” alcanzó tal vez su clímax en 2010 durante los festejos del bicentenario de la Revolución de Mayo representada en clave política del presente, la cultura K devenía en cultura de Estado. Sin embargo, el oficialismo comenzaba a experimentar los límites institucionales y políticos como efectos secundarios de su estrategia de confrontación.

Mientras el ámbito judicial se iba presentando como una arena difícil para avanzar sobre los derechos de ciertos enemigos como el grupo Clarín, el curso de radicalización emprendido comenzaba también a distanciarse de manera creciente de los planes y planteos de líderes peronistas moderados, para quienes el kirchnerismo se estaba volviendo 
cada vez más una costosa carga. Sin embargo, en un nuevo giro de la fortuna ${ }^{18}$ en octubre de 2010 el sorpresivo fallecimiento de Néstor Kirchner emerge como un evento azaroso que por un lado devendría en oportunidad política y simbólica para aventar una probable fractura de la coalición oficial permitiéndole a Cristina Fernández de Kirchner y su gobierno, reconciliarse con la sociedad a partir de su nuevo status de viuda. Sin embargo, el deceso de Néstor Kirchner iba a provocar una herida insalvable a futuro, comprometía el mecanismo sucesorio alternado que en caso de acompańamiento de la sociedad, les permitiría a los Kirchner una permanencia sine die en el poder.

Fiel a la tradición K, en el nuevo escenario la presidenta aprovecharía la ocasión para relanzar su gobierno y mantener la iniciativa, lo que le permitiría ser reelecta un ańo más tarde por el $54 \%$ de los votos. Ante ese nuevo panorama la estrategia escogida fue afianzar y profundizar "El Modelo", eso implicó desde una radicalización del discurso a través de la vuelta a una oratoria de estilo populista clásico, separación de esferas decisorias de todo aquel que no se subordinase a la voluntad del vértice, embates y contiendas con el Poder Judicial, organismos de control del Estado, subestimación y ataques discursivos constantes a las oposiciones, hasta un radical cambio de la economía puesta al servicio de ese objetivo, lo cual alienó a gran parte de actores económicos, políticos y sociales, tanto internos como externos.

La Argentina de Cristina Kirchner se radicalizaba hacia dentro y hacia fuera, lo cual ha traído no pocos inconvenientes en el plano interno (relación con la Iglesia Católica, empresarios, intelectuales, alta inflación, caída de la inversión, etc.) como en el internacional (deterioro en la relación con EEUU, Holdouts, el caso Irán, tensiones con Brasil, etcétera.). Sin embargo no todos esos “combates" fueron perniciosos ni inútiles. Temas como la ley de matrimonio igualitario, la discusión sobre el rol de los medios, o sobre el funcionamiento del Poder Judicial, la politización de sectores juveniles, así como la expansión del mercado interno, han tenido consecuencias positivas en la vida diaria de la sociedad.

18 Cuando hablo de virtud y fortuna, es en clave maquiaveliana. 


\section{¿Epílogo del modelo?}

Para bien o para mal, el sistema institucional está marcando el final del segundo mandato de $\mathrm{CFK}^{19}$, y dada la dinámica política nos podemos preguntar si, ¿es el fin de un gobierno, o el de un estilo de gobierno? La gran incógnita actual gira en torno de un futuro sucesorio que se presenta complejo tanto para el oficialismo, como para las oposiciones ${ }^{20}$.

Habíamos comenzado el artículo hablando sobre un conflicto de legitimidades en pugna, y sin duda ese trasfondo tińe el complejo panorama electoral presente. Sin embargo, creo útil seńalar que aquello que aparece magnificado por el momento agonal durante las campańas políticas, en realidad no alcanza a mi criterio para sostener como hacen oficialismo y oposición, que lo que está en juego sean hegemonías ${ }^{21}$ en pugna.

En todo caso una clave posible para comprender el momento será el reconocer un clivaje entre una democracia con predominio de los modos liberal/republicanos vs otra con predominio de los modos populistas (Panizza, 2009). Si bien el estilo K devino en un intento de predominio, nunca logró un manejo hegemónico del país tal como algunos intelectuales "orgánicos” hubiesen deseado, ni tampoco como algunos opositores denuncian. A mi criterio el kirchnerismo que en algún momento inicial se presentó como una posible instancia superadora de viejas identidades políticas argentinas, termina dejando el poder como otra máscara más del peronismo subterráneo y perenne en las formas y la cultura política, y sin poder siquiera terminar de controlar la sucesión, en un escenario donde viejos problemas de la historia argentina han vuelto al presente.

A modo de desafío quedan para la sociedad y el sistema político superar el cinismo apolítico de vastos sectores sociales que realimenta la debilidad del sistema de partidos, afianzar un federalismo moderno

19 En octubre los argentinos elegimos nuevo gobierno.

20 Uso el plural dada la heterogeneidad del campo opositor.

21 Desgraciadamente el concepto gramsciano de hegemonía aparece bastante tergiversado o "lavado" en el discurso oficialista. 
y eficaz, y volver a consensos mínimos de gobierno que a largo plazo generen posibilidades de bienestar y desarrollo.

\section{Bibliografía}

Acuña, C. (2013). “¿Cuánto importan las instituciones?”. En Gobierno, Estado y actores en la politica Argentina. Buenos Aires: Siglo XXI editores.

Botana, N. (1977). "El orden conservador". En La politica argentina entre 1880 y 1916, 5. Buenos Aires: Edhasa.

Casullo, M. (2015). "Argentina: del bipartidismo a la democracia peronista”. Nueva Sociedad, Nro.258. Julio-Agosto.

Germani, G. (2003). "Autoritarismo, Fascismo y populismo nacional”. Buenos Aires: Temas.

Laclau, E. (2005). La razón populista. Buenos Aires: FCE.

Malamud, A. y Miguel De Luca. (2012). La politica en tiempos de los Kirchner. Buenos Aires: Eudeba.

Mouffe, C. (2007). En torno a lo politico. Buenos Aires: FCE.

Mustapic, A. (2013). Los partidos en la Argentina: condiciones y oportunidades de su fragmentación. En ¿Cuánto importan las instituciones? Gobierno, Estado y actores en la politica Argentina. Carlos Acuña. Buenos Aires: Siglo XXI editores.

Nino, C. (2005). Un pais al margen de la ley. Buenos Aires: Ariel.

Novaro, M. (2012). "La cultura política y el sentido común bajo el kirchnerismo". En La politica en tiempos de los Kirchner. Andrés Malamud y Miguel De Luca. Buenos Aires: Eudeba.

O’Donnell, G., Osvaldo Iazzetta y Hugo Quiroga (2011). Democracia delegativa. Buenos Aires: Prometeo.

Oszlack, O. (1997). La formación del Estado argentino. Buenos Aires: Ariel.

Panizza, F. (2009). El populismo como espejo de la democracia. Buenos Aires: FCE. 
Pérez Liñán, A. (2009). Juicio politico al presidente y nueva inestabilidad politica en América Latina. Buenos Aires: FCE.

Paramio, L. (2006). "Giro a la izquierda y regreso del populismo". Nueva Sociedad Nro.205. Septiembre-Octubre.

Schmitt, C. (2002). Concepto de lo politico. Buenos Aires: Struhart \& Cía.

Tonelli, L. (2012). "Prefacio". En La política en tiempos de los Kirchner. Andrés Malamud y Miguel De Luca. Buenos Aires: Eudeba.

Torre, J. (2003). "Los huérfanos de la política de partidos. Sobre los alcances y la naturaleza de la crisis de representación partidaria". Desarrollo Económico Nro .42.

Tsebelis, G. (1990). Nested Games. University of California Press, Berkeley.

Zelaznik, J. (2012). "Materiales para el studio del sistema político argentino (1999-2011)". En La politica en tiempos de los Kirchner. Andrés Malamud y Miguel De Luca. Buenos Aires: Eudeba. 